\title{
Use of the partogram in a private hospital in South Africa
}

\section{Abstract}

Objective: to explore and describe the use of the partogram in private hospitals in South Africa.

Design: an explanatory mixed method design. In-depth interviews were conducted with the midwives and midwife specialist to explicate the significance of the initial quantitative questionnaires.

Setting: a private maternity hospital in Gauteng Province, South Africa.

Participants: eleven midwives and 3 midwife specialists working in the labour unit of the private maternity hospital.

Findings: although all the midwives and midwife specialists knew the purpose of the partogram, where to find the recommendations on the use of the partogram and the signs of true labour, not all were sure when the partogram had to be completed and who the accountable person for plotting the findings should be. Foetal heart rate monitoring during the active phase of labour remains a concern.

Key conclusion: the findings revealed that the midwives understood the importance of the partogram but are not using it within the parameters for which it was intended. The obstetricians intervened during labour with no or little use of the partogram.

Implications for practice: the study identified the knowledge, strengths and deficits of midwives working in a private hospital on partogram use that would benefit from training interventions and professional development. Evidence suggests a culture where the partogram is not central to care as obstetricians are not using the partogram. The purpose of the partogram in the private sector needs to be reviewed. 


\section{Introduction}

The maternal mortality ratio (MMR) in South Africa is 269 per 100,000 live births (Pettifor, 2015). South Africa has not been able to reverse its maternal mortality ratio possibly because deaths in the community is under-reported (Mmusi-Phetoe, 2016). Of note is that the reported MMR for South Africa consists only of the facility-based maternal deaths. The institutional maternal mortality ratio (iMMR) in South Africa decreased from 176.22 per 100,000 live births in $2008-2010$ to 154.06 per 100,000 live births in 2011-2013 (Saving Mothers 2011-2013) and 134.3 per 100,000 live births in 2014-2015 (Bhardwaj et al., 2018).

The iMMR for private hospitals is approximately 45 per 100,000 live births (Saving Mothers 2011-2013). This may be due to early intervention and the high caesarean section rate in the private sector. Approximately $67 \%$ of births in the private sector of South Africa are conducted by caesarean section, similar to studies conducted in Mexico. Caesarean birth in the private sector in South Africa has become standard practice, with no clear medical indication. As in Mexico, most caesarean sections performed are either elective or due to obstetric convenience and the practice of admitting women to labour wards before they are in active labour (Aranda-Neri et al., 2017). Although the number of maternal deaths are much lower in the private sector, the pattern of disease resulting in maternal deaths is similar. Haemorrhage associated with caesarean section occurred in $17 \%$ of private cases, compared to one third of cases in the public sector (Saving Mothers 2011-2013, Saving Mothers 2014-2016). It is reported that all women in the high resource private sector in South Africa are monitored with the partogram during the intrapartum period as recommended by the World Health Organisation (WHO, 2016). It also appears however, that this does not necessarily bear a direct relationship to mode of birth.

Intrapartum monitoring and early detection of abnormal labour progress can significantly improve the outcome of labour (Tayade and Jadhao, 2012). There appears to be conflicting evidence in terms of routine partogram use and improved outcomes for women and newborns (Bedwell et al., 2017). Two Cochrane reviews (Lavender et al., 2013, Lavender et al., 2018) concluded that routine use of the partogram for labour surveillance did not improve the clinical results for the mother and infant. Midwives find partogram use to have practical benefits in terms of ease of use, time resourcefulness, continuity of care and educational assistance, but routine 
use may reduce midwife autonomy and limit the flexibility to treat each woman as an individual (Weerasekara, 2014). Quality-of-care audits of 163 South African facilities identified a reduction of perinatal mortality rates in some facilities and an increase in others (Allanson and Pattinson, 2015). The contributing factors identified in the audit included foetal distress not detected with monitoring and poor progress of labour with incorrect interpretation of the partogram. The partogram provides healthcare professionals a pictorial overview of the foetal condition, progress of labour and maternal condition to allow early identification and diagnosis of pathological labour (Salama et al., 2010). South Africa adopted a partogram with 2 hour action line that represents the extreme of poor progress where 'action' such as transferring the woman from a clinic to hospital, oxytocin infusion or caesarean section is mandatory (Guidelines for Maternity Care, 2015).

Despite the use of the partogram, it has been observed in South African tertiary, district and private hospital, that midwives do not record appropriately on the partogram when monitoring women in labour. Midwives either do not plot the partogram, plot inaccurately and then do not analyse or interpret the findings correctly, or only plot after delivery of the baby. An unpublished audit of 38 files at a district hospital in 2013 by a community of practice group to determine completion of the partogram during the active phase of labour revealed the foetal heart rate was recorded half-hourly on 10 of the 38 partograms and contractions and the maternal condition on 14 of the 38 partograms.

In a study conducted by Shokane et al. (2013) in Limpopo Province of South Africa, most of the midwives indicated that they failed to monitor and plot their finding of the latent and active phase of labour correctly as the partogram had too many details to complete. The study also found that the majority of the participants knew to examine and assess progress of the women during labour, but lacked knowledge in terms of cervical dilatation. Konlan et al. (2016) reported similar findings in Ghana. Findings overall suggest inadequate knowledge and skills on partogram use.

It is likely that there is a number of contributory knowledge factors associated with inappropriate use of the partogram. Insight into maternal care providers' perceptions and use of the partogram could identify those factors related to partogram use in the clinical environment. Inappropriate use of the partogram is a complex problem as it involves doctors, midwives and their respective students as users. As there may be differences in partogram recording between the private and public sectors, a large 
baseline study that included private, tertiary and district hospital sites was undertaken to identify areas for improvement. Of interest in particular is that no previous studies on the use of the partogram in private hospitals in South Africa could be found. The aim of this paper is therefore to present the findings related to the use of the partogram in a private maternity hospital context, where patterns of mode of birth are particularly skewed.

\section{Methods}

The study adopted a pragmatic approach where the research question drove the inquiry, and both deduction and induction could be accomplished (Cresswell and Plano Clark, 2007). An explanatory mixed method design was followed to integrate data derived both quantitatively and qualitatively in two phases (Polit and Beck, 2017). The qualitative data of the interviews were used to explicate the significance of the initial quantitative results from a questionnaire. Ethical approval was granted by the Ethics Committees of the Faculty of Health Sciences, University of Pretoria (313/2013) and a private hospital (UNIV-2014-0032).

\section{Setting and study sample}

The study was conducted in a private maternity hospital in Gauteng Province, South Africa in July 2015. The hospital specialises in maternity care and has a dedicated 10 bed antenatal unit, high-risk unit, a labour ward with 4 beds for the latent and active phase of labour respectively, 22 bed neonatal intensive care and 40 beds postnatal unit. Approximately 180 births are conducted monthly and the caesarean rate is around $62 \%$. Midwives and midwife specialists care for women during the first stage of labour and private obstetricians conduct the births. Midwife specialists are trained in advanced intrapartum interventions such as conducting a vacuum extraction. Approximately $40 \%$ of patients are induced and analgesic medications including epidural analgesia are used to relieve pain. The use of a partogram with a 2 hour and 4 hour action line is incorporated in the maternity book that includes all the records to be completed during labour. Regular in-service training is provided in the ward by the unit manager and in the skills laboratory of the 
hospital. The conditions described above are reflective of common birthing practice in private hospitals in South Africa. Purposive sampling was used to recruit as many midwives as possible. Fourteen of the seventeen midwives and midwife specialists working in the hospital participated in the study. Eleven of the participants were midwives and three midwife specialists. The other three midwives were either on leave, busy with patient care or not on duty during the visits.

\section{Tools of data collection}

A self-report structured questionnaire was designed to record demographic information including number of years qualified and experience, perceived purpose of the partogram, where to find the recommendations on the use of the partogram, signs of true labour, when to complete the partogram, monitoring of foetal wellbeing in active labour and the person responsible to plot the partogram. As this was a collaborative study, both researchers agreed on the questions to be included in the questionnaire. Some questions included more than one partially correct answer that served as distractors. Only one answer was totally correct.

The questionnaire was pre-tested on midwives enrolled for the master's degree in Advanced Midwifery and Neonatal Nursing at the University of Pretoria to assess face and content validity, which refers to the degree to which an instrument measures what it is supposed to measure (Polit and Beck, 2017). The students took five minutes to complete the questionnaire.

The qualitative interviews that followed the questionnaires were semi-structured in nature and were designed to prompt the midwives to confirm, clarify and elaborate on the questions included in the questionnaire as well as exploring when they would stop plotting the partogram and the meaning of the alert and action line. Semistructured interviews can provide researchers the opportunity to cover a set of topics in their interviews with a written topic guide which is a list of questions on the areas (Polit and Beck, 2017).

\section{Data collection}

The data was collected by the researcher residing in South Africa. The self-report structured questionnaires were handed out in the labour ward at the beginning of 
each visit. The midwives were informed about the aim of the study and were given an information leaflet before handing out of the questionnaire. The midwives only completed the questionnaire if they had at least 10 minutes available during a break or between patient care to pay full attention to the questions. After reading an information leaflet, the midwives on the shift then signed informed consent before being interviewed. Participation was voluntarily and the midwives were informed of their right to confidentiality, anonymity and right to withdraw from the study. The individual face-to-face semi-structured interviews were held in a private room to facilitate privacy and were audio recorded. Interviews lasted anything from 5 to 13 minutes.

\section{Data analysis}

Given the nature of the sampling and the sample size of the private maternity hospital, the statistical analysis of the questionnaires was descriptive using frequencies as presented in a table (Table 1). The interview data was transcribed verbatim and analysed by MY. Data analysis is a process of organizing, providing structure and fitting data together to produce meaning (Polit and Beck, 2017). A lineby-line approach (Schneidere et al., 2008) was used to break the data up into smaller, manageable units. The two researchers (MY and JJ) then discussed the data to confirm agreement with the themes identified, and that they were a true reflection of the midwives narratives. Further discussions facilitated the overall integration of the quantitative and qualitative findings.

\section{Validity, reliability and trustworthiness}

Confirmation of the validity and reliability of tools used in research is according to DeVon et al. (2007) a prerequisite for assuring the integrity of the findings. The questions to determine the use of the partogram are derived from findings of a partogram audit conducted by the community of practice group at one affiliated hospital. The knowledge of the midwives related to the use of the partogram. The questionnaire was pre-tested to increase the face and content validity. The reliability of the questionnaire was not tested. All questions included in the questionnaire 
aimed to assess the knowledge of midwives working in a private hospital on the use of the partogram.

Trustworthiness of the qualitative data collection responded to rigour specifically in the areas of credibility, dependability, confirmability and transferability. Prolonged engagement and reflexivity were used as credibility strategy. The researcher adjusted the questions where necessary in order not to mislead the participants. Investigator triangulation supported trustworthiness and data triangulation with the quantitative data supports validity (Creswell and Plano-Clark, 2007).

\section{Findings}

Of the 14 midwives who participated in the study, six had two to five years of experience, five had more than 5 years of experience and the three midwife specialists had more than 5 years of experience. Interviews were conducted with all the midwives who completed the questionnaire.

The quantitative and qualitative data were integrated and Table 1 summarises the six knowledge themes addressed in the questionnaire. Given the nature of sampling and sample size, the analysis was descriptive.

\section{Table 1}

Knowledge of midwives

\begin{tabular}{lcc}
\hline Themes & Midwives & $\begin{array}{c}\text { Midwife } \\
\text { specialists }\end{array}$ \\
\hline Purpose of the partogram & 10 & 2 \\
\hline Observes the maternal condition & 9 & 2 \\
Observes the foetal condition & 11 & 3 \\
Identifies the progress of labour & 8 & 2 \\
Identifies all treatment given during labour & 11 & 3 \\
Summarises the findings during labour & 2 & \\
\hline Where to find recommendations on partogram use & 2 & \\
Saving Mothers Reports & 5 & 3 \\
Saving Babies Reports & 11 & 1 \\
Essential Steps in the Management of Common & 4 & \\
Conditions associated with Maternal Mortality & & \\
Guidelines for Maternal Care in South Africa & & \\
Saving Lives at Birth & & \\
\hline Signs of true labour & & \\
\hline
\end{tabular}




\begin{tabular}{lcc}
\hline Lower abdominal pain & 3 & 1 \\
Dilatation and effacement of the cervix & 11 & 3 \\
Rupture of the membranes & 3 & 1 \\
A low presenting part & 7 & 1 \\
A show & 1 & \\
\hline When to complete the partogram & 2 & 2 \\
\hline Admission in the labour ward & 5 & 1 \\
The latent phase of labour & 4 & \\
The active phase of labour & 1 & 2 \\
The latent and active phase of labour & & 1 \\
After the birth of the baby & 2 & 1 \\
\hline Monitoring of foetal wellbeing in active labour & & \\
\hline hourly & 9 & \\
4 hourly & & 3 \\
Every 30 minutes & 4 & 1 \\
Bourly & & 1 \\
\hline Persore, during and after every contraction & 9 & 2 \\
\hline Midwives & 4 & \\
Student midwives & 3 & \\
Medical students & 9 & \\
The person who examines the patient & & \\
\hline
\end{tabular}

All questions were answered and in some instances more than one block was ticked. As shown in Table 1, the varied responses of the midwives may indicate that they were uncertain of the correct answer. For instance, a number of midwives ticked the blocks next to correct and incorrect documents on where to find recommendations on partogram use. This could indicate gaps or inconsistencies in knowledge on partogram use. It is a general accepted practice in the hospital to complete the partogram only in the active phase of labour due to the high induction rate. Plotting the partogram during admission and after the birth of the baby, as well as two hourly foetal heart rate monitoring indicated by two midwives reflect poor skills of some midwives on the partogram.

In reporting the identified themes in the qualitative interviews (see Table 1), midwives are identified by the use of ' $M$ ' and midwife specialist by 'MS' with the interview number. All knew the purpose of the partogram:

Purpose of the partogram 
The purpose of the partogram is to help us to manage the patient in labour to see and observe the progress of labour and detect any poor progress of labour so that we can make effective decisions. M9.

Where to find recommendations on partogram use

The midwives commented that the recommendations are available in the unit or can be obtained from the Department of Health:

They're in our files here in the cupboard. M6.

Signs of true labour

Although it was evident that most midwives knew that cervical dilatation and effacement should take place, some midwives relied on less evidenced aspects:

It will be the show...No, it can be two signs, it can be one sign. But if there's a show you know that the patient is in labour. MS4.

True signs of labour is the patient who's having low abdominal pains radiating to the back, then, whereby the cervix is starting to efface and dilate and then there might be a show on a glove when you PV the patient (per vaginal examination). M9.

It will be first of all um, the rupture of membranes. M11.

\section{Completion of the partogram}

Even though the general accepted practice in the hospital is to complete the partogram from the active phase of labour, there is lack of consensus amongst midwives:

When the patient is in active phase of labour, from $4 \mathrm{~cm} . \mathrm{M} 2$

I normally complete my partogram when the patient is in the active stage of labour from three centimetres. M9.

Immediately, I start when the patient is in latent phase of labour. M12.

There was also confusion about when to add new information and when to stop plotting: Though one midwife indicated recording the partogram after the birth of the 
baby, she clarified during the interview that it only applies when she is busy with the delivery.

You start it as soon as the patient is in active labour and you complete it when the baby is born... But when you are busy with delivery obviously you do it when you are done. M2

Knowing the components of the partogram also includes monitoring the maternal and foetal wellbeing.

You are going to do your BP, temperature and maternal pulse hourly and then you will act on what your findings are. MS4.

You are supposed to test urine during, during labour, but I must say that's not, it's not done here. M5.

It appeared that the midwives became confused between the action and the alert lines:

If you get to the second alert line, then usually the doctors take the call and they usually then do a Caesar. M13.

I actually take action on the alert line. I don't wait that late. MS14

Monitoring of foetal wellbeing in active labour

Monitoring of the foetal heart rate to determine the foetal wellbeing was reported to be recorded as follows:

We do intermittent CTG's mainly two hourly and then hourly or half-hourly depending on how you're feeling about the previous CTG and the condition of the baby. You can just auscultate the foetal heart as well before a contraction, during a contraction and after a contraction. M5.

Only one midwife indicated monitoring the foetal heart rate less than half-hourly in active labour:

Active phase of labour, observations, the foetal heart rate um, every, every four hours except if the patient is um, fully dilated. Then you do it after every, every push and before a contraction, after a contraction. M11. 
Using the partogram collaboratively

Midwives reported that not all obstetricians are using the partogram and hierarchical rather than collaborative working seems evidence, though midwives clearly see themselves as advocates for women within the process. Not all midwives trust the findings of the doctors:

If the doctor tells me the patient is $4 \mathrm{~cm}$ dilated, I will go and do the examination myself. M2.

There is one doctor whom l've seen plotting on a partogram, but that was the only doctor. But they normally don't. M9.

\section{Discussion}

The aim of the study was to explore and describe the use of the partogram in a private maternity hospital using interviews to explicate the significance of the quantitative questionnaire findings. No South African studies could be found on partogram use in private hospitals. As there is a much higher incidence of caesarean sections in the private sector, the researchers suspected that the partogram was not used for the purpose it is intended. Knowledge of the partogram among the midwives in this study is relatively good when compared to other studies. This could be due to the supportive organisational policy that is promoting the use of the partogram and a manageable workload.

Literature suggest that duration worked in the labour ward implies more labour management experience and use of the partogram (Mathibe-Neke et al. 2013; Opiah et al. 2012). It is difficult to determine exactly what constitutes enough experience, but the majority of midwives had more than five years of clinical experience, suggesting that experience alone is not the primary influential dictating factor.

All midwives except for one knew where to find recommendations on partogram use in the unit. The labour ward manager reported that she and the clinical facilitator provide frequent in-service training on completion of the partogram. Previous work (Wakgari et al., 2015) also reported a significant association between in-service training and knowledge on partogram use. Good knowledge levels of midwives on partogram use were also reported by studies conducted in Addis Ababa, Ethiopia 
(Yisma et al., 2013), Nigeria (Opiah et al., 2012) and Gambia (Burama et al., 2013). Zambian midwives have acquired sufficient understanding regarding the usefulness of the WHO partogram (Fujita et al., 2015) and although Ghana midwives knew the supposed partogram use, some were trained before mandatory use of the partogram (Konlan et al., 2016).

The midwives in this study and midwives from another study in Vhembe District, South Africa, stated the progress of labour can be seen clearly on the partogram, completing the partogram saves time and the findings can easily be reported to colleagues (Lumadi, 2015). Most midwives in this study mentioned the parameters for progress of labour (contractions, cervical dilatation and descent). Only $55-60 \%$ of midwives mentioned the parameters for progress of labour in a study conducted in Ghana (Opoku and Nguah, 2015). Early intervention without the use of the partogram is a concern. The poor use of the partogram by obstetricians could explain the high incidence caesarean section (62\%) rate in the private hospital. According to Aranda-Neri et al. (2017), nearly two-thirds (65.6\%) of caesarean sections were performed in Mexico before women were in active labour.

Identifying true labour is a concern. Eight midwives regarded a show as a sign of true labour which could imply plotting of a false latent phase of labour. Participants in another South African study also indicated that a show, uterine contractions, cervical effacement and cervical dilatation are all true signs of labour (Shokane et al., 2013). Women admitted before $4 \mathrm{~cm}$ may progress very slowly, and could take up to 24 hours before achieving full cervical dilatation (Oladapo et al. 2017). Women in early or false labour may be admitted unnecessarily with increased vaginal examinations, misdiagnosed as labour protraction or arrest (Zhang and Duan, 2017) and inappropriate augmentation of labour (Bedwell et al, 2017).

When to complete the partogram depends strongly on the obstetric knowledge of maternal care providers. Although the ward policy is not to complete the latent phase of labour on the partogram, midwives lack consensus on whether the active phase of labour starts at three of four centimetres of cervical dilatation. Identifying the latent phase of labour seems to be a common problem (Ollerhead and Osrin, 2014). Identifying the specific time to commence recording on the partogram was a problem in Ghana (Konlan et al., 2016). When to start plotting the partogram was a problem in Ethiopia (Zelellw et al., 2016). Poor practices such as completing the partogram after delivery as indicated by one midwife in this study are also well described by 
numerous studies in Ollerhead and Osrin (2014). Regarding the time of stopping the partogram, about one third of maternal caregivers continued until complete cervical dilatation, while the others stopped plotting before that (Salama et al., 2010). New insights in the overall labour progression data in a systematic review by Oladapo et al. (2017) shows that the expectation of a minimum cervical dilatation threshold of 1 $\mathrm{cm} /$ hour throughout labour is unrealistic for most healthy nulliparous and parous women. In addition, cervical dilatation patterns for low-risk women are not linear and tend to only become accelerative (i.e. $>1 \mathrm{~cm} /$ hour) between 5 and $6 \mathrm{~cm}$ in both nulliparous and parous women. Given the current level of debate in the literature regarding definitions and management of prolonged labour (White et al., 2017), parameters for labour progress may soon change.

Blood pressure and pulse is monitored hourly and urine tested 2 hourly for proteins and ketones to manage a pregnant woman with no risk factors in active labour (Guidelines for Maternity Care in South Africa, 2015). Parameters pertaining to monitoring of maternal wellbeing such as pulse, blood pressure, temperature and urine were reported to be monitored by $44 \%$ of midwives in a South African study by Mathibe-Neke et al. (2013), and only in about $40 \%$ of cases in Ghana (Opoku and Nguah, 2015). Although the compliance rates of maternal pulse (25\%) was low in Zambia, most midwives considered blood pressure to be the most important item for early detection of pre-eclampsia and eclampsia (Fujita et al., 2015). More (68.1\%) obstetric caregivers in Ethiopia knew that urine volume, protein, and ketone bodies are components in monitoring of the maternal conditions (Zelellw et al., 2016).

A knowledge gap in the functions of the alert and action line was identified in this study, similar to that identified in Ethiopia (Abebe et al., 2013; Zelellw et al., 2016). Only about half of the midwives were able to correctly mention the function of both lines. Rouse et al. (2001) demonstrated that $61 \%$ of women with a 2 hour arrest of labour in the active phase were able to deliver vaginally. A trial by Lavender et al. (2006) showed that intervention in slow labour based on an action line 2 hours to the right of the "normal" progress line is more common, but does not result in improved outcomes compared with intervention based on a 4-hour action line. White, Lee and Beckman (2017) also report that Australian obstetricians commonly use partograms, but fewer than half of obstetric providers draw action and alert lines, and there is little agreement as to when to draw these and what to do when they are crossed. 
The foetal heart rate is monitored half hourly in a pregnant woman with no risk factors in the active phase of labour (Guidelines for Maternity Care in South Africa, 2015). All the midwives in this study except for one indicated half-hourly foetal heart rate monitoring in active labour. Though intermittent auscultation is used in the private hospital, the midwives seemingly revert to use of the cardiotocograph (CTG). This may be due to the availability of the CTG machine in each labour room and other reasons such as habit, liability concerns, resistance to evidence-based practice and convenience. CTG is also the most common form of intrapartum foetal assessment in the United States (Hersh et al., 2014). Intermittent auscultation is acceptable for low-risk women, but underutilised in private hospital settings. The CTG enables midwives to pick up suspicious or abnormal foetal heart rate tracings that are reported to the obstetricians. Not all suspicious tracings are an indication of foetal distress. A high caesarean section rate could be an indication that midwives do not always interpret the CTG correctly and call obstetricians prematurely before implementation of strategies such as altering the maternal position. Obstetricians may also conduct unnecessary caesarean sections due to the high litigation in the private sector of South Africa. It is therefore necessary to improve compliance of intermittent foetal heart rate auscultation to monitor the foetal wellbeing and further investigate the reasons for the high caesarean section rate. The foetal heart rate was not always monitored during the second stage of labour at a primary health centre in Zambia (Fujita et al., 2015) and Ghana (Opoku and Nguah, 2015).

In this study only one obstetrician completed the partogram. Doctors are not seen plotting the partogram in South Africa (Lumadi, 2015), but make decisions and intervene with no or little use of the partogram. According to Vlachos et al. (2015), indications for caesarean section such as labour abnormalities, foetal distress, maternal age and parity are often over-diagnosed, and the partogram may be a useful tool to detect early problems or confirm normality.

Quality record-keeping promotes effective communication between midwives and obstetricians and assists in collaborative decision-making. Interprofessional midwifephysician collaboration is still an emerging concept globally (Smith, 2015). Although doctors displayed positive attitudes towards the partogram, positive attitudes alone do not translate into partogram use in practice due to the availability, time, workload and organisational culture (Bedwell et al., 2017). According to White et al. (2017), $89.0 \%$ of Australian obstetricians routinely use the partogram to assess the progress 
of labour. All the obstetricians including those in the private sector should know the partogram from their training and obligated by hospital policy.

\section{Conclusion}

This study revealed an understanding of the use of the partogram. A lack of use of the partogram is often associated with poorer maternal and foetal outcomes in low income countries. Literature report mainly on studies conducted in high-income settings and may not have included all relevant outcomes or were not used in practice effectively. Although the use of the partogram is compulsory in all obstetric settings in South Africa, completion of the partogram in the selected private hospital was not a challenge for midwives possibly due to the frequent in-service training on partogram use provided by the clinical facilitators and unit managers. What is of concern is the high caesarean section rate in the private sector possibly due to obstetricians not using or basing their clinical decisions-making on the partogram.

A limitation of this study is that the numbers of the participants were few and the findings cannot be generalised to all private hospitals. More in-depth interviews would have given more opportunity to explore the challenges and deficits in partogram use, but were limited by the time and availability of the midwives. Obstetricians were also not included in the study. A positive attitude towards the partogram may not mean the use of the partogram and the extent of interpretation and guidance of the actual management of labour in the private hospital. As obstetricians are not making all the decisions based on the partogram, the question is raised on what their decision-making is based. Linking partogram use with a management protocol could prompt better clinical assessment and overcome gaps in decision making and the action taken by obstetricians. Midwives only monitor the progress of the women during labour and have limited input in the decision making process during labour, limiting the midwife-physician collaboration. This could be a further investigation. The use of the partogram in the specific private hospital can therefore be questioned, and it is likely that partogram use in other private hospitals may be similar. The extent of the identified deficit between guidelines, practice and interprofessional collaboration between midwives in other private hospitals should 
further be explored. It is also important to explore the practices of partogram use in state funded hospitals and compare these findings.

Authors' contributions

\begin{tabular}{|l|c|c|}
\hline Authors' contributions & MY & JJ \\
\hline Research concept and design & $\sqrt{ }$ & $\sqrt{ }$ \\
\hline Collection and/or assembly of data & $\sqrt{ }$ & \\
\hline Data analysis and interpretation & $\sqrt{ }$ \\
\hline Writing the article & $\sqrt{ }$ & $\sqrt{ }$ \\
\hline Critical review of the article & & $\sqrt{ }$ \\
\hline Final approval of the article & $\sqrt{ }$ & $\sqrt{ }$ \\
\hline
\end{tabular}




\section{References}

Abebe, F., Birhanu, D., Awoke, W., Ejigu, T., 2013. Assessment of knowledge and utilization of the partograph among health professionals in Amhara region, Ethiopia. Science Journal of Clinical Medicine 2(2), 26-42.

Allanson, E.R., Pattinson, R.C., 2015. Quality-of-care audits and perinatal mortality in South Africa. Bulletin of the World Health Organization 93, 424-428.

Aranda-Neri, J.C., Suárez-López, L., DeMaria, L.M., Walker, D. 2017. Indications for Cesarean Delivery in Mexico: Evaluation of Appropriate Use and Justification. BIRTH 44, 1.

Bedwell, C., Levin, K., Pett, C., Lavender, D.M., 2017. A realist review of the partograph: when and how does it work for labour monitoring? BMC Pregnancy and Childbirth, 17:31. DOI 10.1186/s12884-016-1213-4.

Bhardwaj, S., Pattinson, R., Kauchali, S., Dlamini, N., Marshall, C., van der Merwe, M., Barron, P., 2018. Implementation of strategies to improve programme effectiveness lead to an improvement in maternal and child health outcomes in South Africa. South African Medical Journal, 108(3suppl1):S44-S49. DOI:10.7196/SAMJ.2018.v108i3.12812

Burama, B., Kao, H.C., Gua, L.M., Lin, C.K., 2013. Partograph use among midwives in the Gambia. AJM 7(2), 65.

Cresswell, J.W., Plano-Clark, V.L., 2007. Designing and Conducting Mixed Methods Research. Sage, California, London.

Department of Health, 2007. Guidelines for Maternity Care in South Africa. http://www.ais.up.ac.za/health/blocks/block9/Maternal\%20Guidelines\%202007.pdf

Department of Health, 2015. Guidelines for Maternal Care in South Africa: A manual for clinics, community health centres and district hospitals. http://www.hst.org.za/sites/default/files/Maternal\%20Care\%20Guidelines\%202015 FINAL.21.7.15.pdf

DeVon, H.A., Block, M.E., Moyle-Wright, P., Ernst, D.M., Hayden, S.J., Lazzara, D.J., Savoy, S.M., Kostas-Polston, E., 2007. A Psychometric Toolbox for Testing Validity and Reliability. Journal of Nursing Scholarship 39(2), 155-164.

Fujita, W., Mukumbuta, L., Chavuma, R., Ohashi, K., 2015. Quality of partogram monitoring at a primary health centre in Zambia. Midwifery 31, 191-196. 
Goldenberg, R.L., McClure, M., 2015. Maternal, fetal and neonatal mortality: lessons learned from historical changes in high income countries and their potential application to low-income countries. Maternal Health, Neonatology and Perinatology 1:3, http://dx.doi.org/10.1186/s40748-014-0004-z.

Hersch, S., Megregian, M., Emeis, C., 2014. Intermittent auscultation of the fetal heart rate during labor: An opportunity for shared decision making. J Midwifery Womens Health 59, 344-349.

Kassebaum, N.J., Bertozzi-Villa, A., Coggeshall, M.S., et al., 2014. Global, regional, and national levels and causes of maternal mortality during 1990-2013: a systematic analysis for the Global Burden of Disease Study 2013. Lancet 384(9947), 980-1004.

Konlan, K.D., Kombat, J.M., Wuffele, M.G., Aarah-Bapuah, M., 2016. Knowledge and attitudes of midwives on the use of the partogram: a study among midwives in the Tamale Metropolis. Maternal Health, Neonatology and Perinatology, 2,2.

Lavender, T., Alfirevic, Z., Walkinshaw, S., 2006. Effect of different partogram action lines on birth outcomes. Obstet Gynecol;108, 295-302.

Lavender, T., Hart, A., Smyth, R.M.D. 2013. Effect of partogram use on outcomes for women in spontaneous labour at term. Cochrane Database Systematic Review, 15(8):CD005461.

Lavender, T., Cuthbert, A., Smyth, R.M.D. 2018. Effect of partograph use on outcomes for women in spontaneous labour at term and their babies. Cochrane Database of Systematic Reviews, 8:CD005461.

Lumadi, T.G., 2015. Attitudes of labour ward staff towards a clinical practice guideline for monitoring women during labour: Midwives' views. AJPHERD, 115123.

Lumadi, T.G., Moleki, M.M., Modiba, L.M., 2015. Challenges experienced by midwives on the use of partogram in Limpopo Province of South Africa. Africa Journal of Nursing and Midwifery 17, 31-45.

Mathibe-Neke, J.M., Lebeko, F.L., Motupa, B., 2013. The partograph: A labour management tool or a midwifery record? International Journal of Nursing and Midwifery 5(8), 145-153.

Mmusi-Phetoe, R.M.M. 2016. Social factors determining maternal and neonatal mortality in South Africa: A qualitative study. Curationis 39(1), a1571. http://dx.doi.org/10.4102/ curationis.v39i1.1571. 
Oladapo, O.T., Diaz, V., Bonet, M., Abalos, E., Thwin, S.S., Souza, H., Perdoná, G., Souza, J.P., Gülmezoglu, A.M., 2017. Cervical dilatation patterns of 'low-risk' women with spontaneous labour and normal perinatal outcomes: a systematic review. BJOG, https://doi.org/10.1111/1471-0528.14930.

Ollerhead, E., Osrin, D., 2014. Barriers to and incentives for achieving partograph use in obstetric practice in low- and middle-income countries: a systematic review. Pregnancy and Childbirth 14, 281, http://www.biomedcentral.com/14712393/14/281.

Opiah, M.M., Ofi, A.B., Essien, E.J., Monjok, E., 2012. Knowledge and utilization of the partograph among midwives in the Niger Delta Region of Nigeria. African Journal of Reproductive Health 16(1),125-132.

Opoku, B.K., Nguah, S.B., 2015. Utilization of the modified WHO partograph in assessing the progress of labour in a metropolitan area in Ghana.

Pattinson, R.C., Rhoda, N. 2012-2013. Saving babies. Ninth report on perinatal care in South Africa. Pretoria: Department of Health.

Pettifor, J. M. 2015. Perinatal statistics - some good news. South African Journal of Child Health, 9(1):2.

Polit, D.F., Beck, C.T., 2017. Nursing research: generating and assessing evidence for nursing practice. 10th ed. Williams \& Wilkins, Philadelphia.

Rouse, D.J., Owen, J., Savage, K.G., Hauth, J.C., 2001. Active phase labor arrest: revisiting the 2-hour minimum. Obstet Gynecol 98, 550-554.

Salama, N.S., Allah, I.M.A., Heeba, M.F., 2010. The partograph: knowledge, attitude, and utilization by professional birth attendances in Port-Said and Ismailia cities. Medical Journal of Cairo University 78(1), 165-174.

Schneider, Z., Whitehead, D., Elliot, D., Lobiondo-Wood, G. \& Haber, J. 2008. Nursing and Midwifery Research: Methods and Appraisal for Evidence Based Practice. 3rd Edition, Sydney: Mosby Elsevier.

Shokane, M.A., Thopola, M.K., Jali, M.N., Kgole, J.C., Mamogobo, P.M., 2013. The utilization of the partograph by midwives in Lebowakgomo and Zebediela Level 1 hospitals in Capricorn district, Limpopo Province, South Africa. African Journal for Physical, Health Education, Recreation and Dance March (1): 159-168.

Smith, D.M., 2015. Midwife-Physician Collaboration: A Conceptual Framework for Interprofessional Collaborative Practice. J Midwifery Womens Health 60, 128139. 
Statistics South Africa. 2015. Perinatal deaths in South Africa. 2011-2013. Retrieved from www.statssa.gov.za/publications/P03094/P030942013.pdf

Tayade, S., Jadhao, P. 2012. The impact of use of the modified WHO partograph on maternal and perinatal outcome. International Journal of Biomedical and Advance Research 03(04), 256-262.

The Millennium Development Goals Report, 2013. Assessing progress in Africa toward the Millennium Development Goals. United Nations: New York.

Vlachos, G., Tsikouras, P., Manav, B., Trypsianis, G., Liberis, V.,Karpathios, S., Galazios, G., 2015. The effect of the use of a new type of partogram on the cesarean section rates. J Turk Ger Gynecol Assoc 16, 145-148.

Wakgari, N., Tessema, G.A., Amano, A., 2015. Knowledge of partograph and its associated factors among obstetric care providers in North Shoa Zone, Central Ethiopia: a cross sectional study. BMC Res Notes 8, 407.

Weerasekara, D., 2014. Usefulness of a Partograph to improve outcomes: Scientific Evidence. SLJOG June.

White, L., Lee, N., Beckmann, M., 2017. First stage of labour management practices: A survey of Australian obstetric providers. Aust N Z J Obstet Gynaecol 57, 266271.

WHO, 2016. Standards for improving quality of maternal and newborn care in health facilities. http://www.who.int.

WHO, UNICEF, UNFPA, and The World Bank and the United Nations Population Division, Trends in Maternal Mortality: 1990 to 2013, "Estimates by WHO, UNICEF, UNFPA, The World Bank and the United Nations Population Division", World Health Organization, 2014.

Yisma, E., Dessalegn, B., Astatkie, A., Fesseha, N., 2013. Knowledge and utilization of partograph among obstetric care givers in public health institutions of Addis Ababa, Ethiopia. BMC Pregnancy Childbirth 13(17), 1-9.

Zhang, J., Duan, T., 2017. The physiologic pattern of normal labour progression. BJOG. Mini commentary. DOI: 10.1111/1471-0528.14929.

Zelellw, D.A., Tegegne, T. K., Getie, G.A., 2016. Knowledge and attitude of obstetric care providers on partograph and its associated factors in East Gojjam Zone, Northwest Ethiopia. Advances in Medicine http://dx.doi.org/10.1155/2016/6913165 